\title{
Work Motivation of Development Agents in Agricultural Extension Services Provision in Minjar Shenkora and Ada'a woredas, Central Ethiopia
}

\author{
Mekonnen Hailu \\ Ethiopian Institute of Agricultural Research, Addis Ababa, Ethiopia
}

\begin{abstract}
This study assessed the work motivation of Development Agents (DAs) and analyzed the major factors that might influence their motivation. The study involves a survey questionnaire of 143 DAs, key informants, and focus group discussants in Minjar Shenkora and Ada'a woredas. Data were analyzed using descriptive statistics like means, standard deviations, frequencies, and percentages. While qualitative data were thematically summarized, narrated, and then interpreted for triangulation. Chi-square and F-tests were used to test the significance of the mean value differences of the categorical and continuous variables, respectively. Pearson's Product Moment Correlation was used to identify factors and to measure the degree of correlation between factor variables related to work motivation. Results of this study showed that about $69 \%$ of DAs were in a medium level of work motivation, while about $21 \%$ of them were in a low level. While analyzing the major factors affecting work motivation, promotion, recognition, competitive salary, dependable supervision, workload, and degree of involvement were highly correlated positively with work motivation of DAs at a $1 \%$ level of significance. Therefore, necessary efforts have to be made to improve the work motivation of DAs in agricultural extension organizations. Thus, concerning agricultural policymakers, extension managers, and supervisors should conduct periodic assessments of work motivation of DA's and have to plan for improvement.
\end{abstract}

Keywords: Central Ethiopia, development agent, extension services, motivation,

DOI: $10.7176 / \mathrm{FSQM} / 112-03$

Publication date: January $31^{\text {st }} 2022$

\section{Introduction}

Agriculture in Ethiopia has played and is still playing a fundamental role in the government's policy and development strategies (Getachew, 2018). It is the primary source of livelihood for the large majority of people live in rural areas of Ethiopia. It provides a living for around 17.7 million Ethiopian smallholder households' (CSA, 2020). Despite its share to the total GDP declining to $32.7 \%$ in recent years, its GDP contribution has increased from 499.8 billion ETB in 2013/14 to 650.3 billion ETB in 2019/20 (MoA, 2020; NBE, 2019/20). The sector also provides $72.7 \%$ of employment opportunities, $90 \%$ of export earnings, and $90 \%$ of raw materials for manufacturing industries (CSA and WFP, 2019). The country has adopted Agricultural Development Led Industrialization (ADLI) as a national strategy for accelerating agricultural development by means of technological and institutional innovations, transforming the production system to that of more productive and markets oriented agricultural development (Belay et al., 2012). Under this strategy, agricultural extension system plays a crucial role to transform smallholder subsistence agriculture to commercial agricultural production system by enhancing adoption of improved agricultural technologies and knowledge.

Effective and demand-driven agricultural extension and advisory services have significant importance for agricultural development and rural transformation (Gerba, 2018; Pye-Smith, 2012). Agricultural development is highly depends on the provision and utilization of improved agricultural technologies and knowledge to the end user. In order to transfer these improved technologies and knowledge rigorous and vibrant extension system is a key policy instrument (MoANR and ATA, 2017). According to Belay and Deginet (2004) the effectiveness of agricultural extension work highly depends on the availability and accessibilities of DAs who are qualified, motivated, dedicated and responsive to the ever-changing social-economic environment. Ethiopia has declared its commitment by trained the largest frontline DA-to-farmer ratios in the world (Fantu et al., 2015; ATA, MoA and EIAR, 2015; Davis et al., 2010).

DAs' work motivation is an important push factor in the job performance. Motivated DAs feel less anxiety, enjoy their work and have better physical and mental strength to accomplish the tasks. DAs are not only required to have the knowledge and skills but must also be well motivated to work under complex conditions (Belay et al., 2012). DAs are major implementers of agricultural extension policies and strategies at the proximity of farmers more than all other actors in the extension system. So, among others the agents are expected to highly motivated and understand the heartbeat of the farmers (Belay et al., 2012). Moreover, development of modernized agriculture and extension system requires competent, energetic, and dynamic workforce (MoANR and ATA, 2017). In order to make employees motivated and committed to their jobs in agricultural and rural development activities, there is a need for strong and effective motivation at the grass root level, sphere head workers in the front line who are 
DAs. DAs will effectively and efficiently discharge his/her responsibilities if and only if, they are highly motivated in their job. According to Dercon et al. (2009) farmers who received at least one DAs visit per year reduces the likelihood of being poor by $10 \%$ in Ethiopia. Although all the extension problems of the provision extension services are not explained solely by the lack of work motivation and job performance of DAs, it took the larger share in the delivery of extension services. Therefore, it is important to assess the work motivation of DAs' and analyzed the major factors that might influence their motivation for appropriate and timely interventions.

\section{Materials and methods}

\subsection{Description of the study areas}

The survey was conducted in Minjar Shenkora woreda of Amhara National Regional State and Ada'a woreda of Oromia National Regional State of Ethiopia. Minjar Shenkora is one of the woredas in the North Shewa Zone of Amhara Regional State of Central Ethiopia. The administrative center of the woreda is Arerti. It is located farther to the southern part of North Shewa Zone, and located at about $135 \mathrm{~km}$ southeast of the Capital city, Addis Ababa. The woreda is composed of a total of 30 kebeles, 27 rural kebeles, and the rest urban kebeles. Tef, wheat, sorghum, and maize are among the cereal crops and chickpea and lentil among pulses grown in the woreda. Ada'a is one of the woredas in East Shewa Zone of Oromia Regional State of Central Ethiopia. The woreda administrative town is Bishoftu, which is located $45 \mathrm{~km}$ away east of Addis Ababa. Altitudes in this woreda range between 1,500 to over 2,000 meters above sea level. Ada'a woreda is a mixed farming, crop production, and livestock production area. Crops grown in the woreda are tef, wheat, barley, maize sorghum, chick pea, horse bean, ground nut, root crops, and vegetables.

\subsection{Type of data and sample size}

Mixed methods of data collection were employed to achieve the objective of the study. The mixed methods approach was chosen because it provides more detailed information about DAs' work motivation in the study areas. A structured questionnaire was used to obtain quantitative data from 143 DAs from Minjar Shenkora and Ada'a woredas. Key informant interviews and focus group discussions were performed to generate qualitative data to supplement the quantitative data. Key informants were identified from agricultural extensionists, heads of agriculture offices, DAs, agriculture cooperatives, model farmers, and community elders. All of the key informants had extensive experience with and knowledge of the extension system and DAs work performance at the national and local levels. Eight separate focus group discussions, each group comprised of 6-10 participants were held with farmers, community elders, and DAs. Moreover, secondary data sources were used from peer-reviewed articles, books, and annual reports, and published and unpublished documents from relevant sources.

\subsection{Method of Data Analysis}

To measure the level of work motivation of DAs, a five point continuum likert-type scale was used except for variables such as age, sex, marital status, family background, distance to work location and working experience (McCaslin and Mwangi, 1994). Work motivation variables were measured by using the scale suggested by Pareek and Rao (1992) with slight modifications. The variables were also measured using a five point continuum likert scale as suggested by Thurstone (1976). The scale used to measure work motivation variables were $1=$ strongly disagree, $2=$ disagree, $3=$ neutral, $4=$ agree and $5=$ strongly agree. The scoring was given in ascending order from 1 to 5 for positive responses. The level of work motivation of DAs constituted the base for scoring by the DA respondent on the dependent variables. The researcher hoped to gain insight into work motivation of a DA to determine the level of their work motivation, since lack of work motivation can lead to low performance. Therefore, the researcher wanted to study work motivation hoping to be able to show a clue to bring a change in work motivation thereby in the organizational performance.

The data thus collected were analyzed using appropriate tools. The quantitative data collected through interviews with farmers, questionnaires administered to DAs and higher officials were analyzed using descriptive statistics such as means, frequencies, percentages and rank order categorization. Dummy and categorical variables were tested using the chi-square test, and continuous variables were used one-way ANOVA to test the significance of the mean value differences. Person's Product Moment Correlation was carried out to identify the important factors that are related to the work motivation of DAs.

\section{Results and Discussion}

\subsection{Work Motivation Level of DAs}

The results of analysis of work motivation of DAs are presented in Table 1. The score of work motivation of DAs in the study areas ranges from 14-38. The actual mean score of work motivation is 24.36 with the standard deviation 5.34. The overall mean of motivational level was 2.89 and standard deviation of 0.73 on a scale of 1 to 5 (1= lowest \& $5=$ highest). The analyses also show that the work motivation of DAs is at medium level. About $66 \%$ of DAs were in the medium category, about $22 \%$ were in low category and only $12 \%$ had highly motivated 
in their job. In addition to the survey results, key informant interviews and focus group discussions were conducted on work motivation of DAs in the study woredas. The analysis indicated that lack of appropriate incentives, lower salary, high workload, engaged in irrelevant to the profession duties and responsibilities, multiple chains of command, and poor infrastructural have mainly influenced the low work motivation and high rate of turnover of DAs.

Table 1: Level of work motivation among DAs in the study areas

\begin{tabular}{|c|c|c|c|c|c|}
\hline Work Motivation Category & Score & f & $\%$ & Actual Mean Score & Actual SD \\
\hline Lower & $14-19$ & 31 & 21.7 & & \\
\hline Medium & $20-30$ & 95 & 66.4 & & \\
\hline Higher & $21-38$ & 17 & 11.9 & & \\
\hline Total & & 143 & 100 & 24.36 & 5.34 \\
\hline
\end{tabular}

Source: Own calculation based on field survey

\subsection{Descriptions of dummy and continuous variables with work motivation}

The analysis of the result in Table 2 shows the extension profession in the study areas is male dominated; about $70 \%$ were male and 30\% were female. Yet, it has been consistently argued that there is a need to have a balance between male and female extension staff to make the extension system gender sensitive. Although there has been an increase in the number of female DAs in the extension system, key informants revealed that the social and cultural factors, harsh working environment and the work load constrained the female DAs to engage in the extension system. However, the chi-square test indicated that there is no relationship between sex and work motivation of DAs at 10\% significant level. This result is in line with the previous studies by Girma (2018) and Yohannes (2009). The marital status of respondents in Table 2 shows that $66.4 \%$ and $32.8 \%$ of DA was unmarried and married, respectively while only $0.8 \%$ was separated. The significance test was undertaken to see the difference between married, unmarried and separated DAs. It was hypothesized to indicate the relationship with work motivation of DAs in favor of married DAs. However, the chi-square test shows that work motivation of DAs and their marital status is not significant at $10 \%$ significance level.

One important factor in agricultural extension work is the DAs' background in farming. According to Belay and Deginet (2004) DAs with rural background have first-hand experience and understanding of farmers' problems and management problems. In this connection, about $88 \%$ and $12 \%$ of the respondents had urban and rural background, respectively. The rural background of DAs was hypothesized to have a positive relationship with the work motivation of DAs and the chi-square test confirmed that there is an association between DAs background and work motivation at 5\% significance level. This result is consistent with study that has shown the association between work motivation and DAs' family back ground indicating that the rural back ground DAs are more motivated than DAs with urban background Debebe et al. (2016), Belay et al. (2012), Tesfaye (2012).

The mean age of DAs' is 26.69 years but there are extreme differences, the oldest being 47 and the youngest 22 years old. About $93 \%$ of the respondents are less than 30 years old (Table 3 ). The mean age of low, medium and high work motivation was 29.73, 26.65 and 25.17 years, respectively. This indicates that older DAs have lower work motivation than younger DAs. DAs must be active and energetic as the work involves a lot of energy demanding activities like traveling, and carrying out a lot of demonstrations materials to farmers. One-way ANOVA (F-test) shows age was highly associated to work motivation of the DAs and significant at $1 \%$. FGD with extension managers, process owners, extension officers and supervisors confirmed that since the working environment of DAs is challenging, most of aged DAs are fed-up on their own work, some of them are out of the job and even some of the aged DAs are living in conditions similar with the farming community they serve as a professional. Because of such reasons, older DAs have less work motivation than the younger DAs. This finding is consistent with a previous study by Girma (2018), Debebe et al. (2015), Zelalem (2011) and Tesfaye (2012). 
Table 2: The association of dummy variables with work motivation of the DAs

\begin{tabular}{|c|c|c|c|c|c|c|c|c|c|}
\hline \multirow{3}{*}{$\begin{array}{l}\text { Demographic } \\
\text { Variables }\end{array}$} & \multicolumn{8}{|c|}{ Motivation Level } & \multirow{3}{*}{$\chi^{2}$} \\
\hline & \multicolumn{2}{|c|}{ Low } & \multicolumn{2}{|c|}{ Medium } & \multicolumn{2}{|c|}{ High } & \multicolumn{2}{|c|}{ Total } & \\
\hline & f & $\%$ & f & $\%$ & f & $\%$ & f & $\%$ & \\
\hline \multicolumn{10}{|l|}{ Sex } \\
\hline Male & 19 & 15.6 & 56 & 45.9 & 10 & 8.2 & 85 & 69.7 & \multirow{3}{*}{1.562} \\
\hline Female & 7 & 5.7 & 28 & 23.0 & 2 & 1.6 & 37 & 30.3 & \\
\hline Total & 26 & 21.3 & 84 & 68.9 & 12 & 9.8 & 122 & 100.0 & \\
\hline \multicolumn{10}{|l|}{ Marital Status } \\
\hline Single & 17 & 13.9 & 55 & 45.1 & 9 & 7.4 & 81 & 66.4 & \multirow{4}{*}{0.857} \\
\hline Married & 9 & 7.4 & 28 & 23.0 & 3 & 2.5 & 40 & 32.8 & \\
\hline Separated & 0 & 0.0 & 1 & 0.8 & 0 & 0.0 & 1 & 0.8 & \\
\hline Total & 26 & 21.3 & 84 & 68.9 & 12 & 9.8 & 122 & 100.0 & \\
\hline \multicolumn{10}{|l|}{ Qualification } \\
\hline Certificate & 0 & 0.0 & 0 & 0.0 & 1 & 0.8 & 1 & 0.8 & \multirow{4}{*}{$12.788 * * *$} \\
\hline Diploma & 14 & 11.5 & 49 & 40.2 & 3 & 2.5 & 66 & 54.1 & \\
\hline Degree & 12 & 9.8 & 35 & 28.7 & 8 & 6.6 & 55 & 45.1 & \\
\hline Total & 26 & 21.3 & 84 & 68.9 & 12 & 9.8 & 122 & 100.0 & \\
\hline \multicolumn{10}{|l|}{ Background } \\
\hline Urban & 5 & 4.1 & 6 & 4.9 & 4 & 3.3 & 15 & 12.3 & \multirow{3}{*}{$8.153 * *$} \\
\hline Rural & 21 & 17.2 & 78 & 63.9 & 8 & 6.6 & 107 & 87.7 & \\
\hline Total & 26 & 21.3 & 84 & 68.9 & 12 & 9.8 & 122 & 100.0 & \\
\hline
\end{tabular}

Note: $\mathrm{f}=$ Frequencies and $* * *$, and $* * *$ denotes significance level at $10 \%, 5 \%$, and $1 \%$.

Source: Own calculation based on field survey

On average, respondents have worked for 4.5 years as DA with the maximum and minimum of 24 and less than a year, respectively (Table 3). But, more that $96 \%$ of the respondents served for less than ten years as DA; among those respondents, about $65 \%$ of DAs served $\leq 3$ years. This clearly shows that there is a high level of turnover among the DAs. The mean working experience of low, medium and high work motivation was $5.58,4.32$ and 3.42 years, respectively. The result from one way ANOVA shows that there is significant association at 5\% level of significance between DAs' work motivation and working experience. The average distance from their residence to their place of duty $13.23 \mathrm{~km}$ whereas the average distance of the lower work motivation DAs was $17.25 \mathrm{~km}$ which is the longer distance than medium motivated $(12.69 \mathrm{~km})$ and high motivated $(8.25 \mathrm{~km})$. According to Spies (2006) long distance leaves DAs tired and lacking energy and poses a problem of travelling costs. Therefore, the longer distance from their homes affects the work motivation of DAs negatively. The result from one way ANOVA confirmed that there is significant relationship at $1 \%$ level of significance between DAs work motivation and the work location. This study is consistent with study by Girma, 2018, Debebe et al. (2015), Yohannes (2009), Zelalem (2011) and Tesfaye (2012).

Table 3: The association of continuous variables with work motivation of DAs

\begin{tabular}{|c|c|c|c|c|c|c|}
\hline \multirow{2}{*}{\multicolumn{2}{|c|}{$\begin{array}{c}\text { Continuous } \\
\text { Variables }\end{array}$}} & \multicolumn{4}{|c|}{ Motivation Level } & \multirow{2}{*}{ F-Test } \\
\hline & & Low & Medium & High & Total & \\
\hline Age & $\begin{array}{l}\text { Mean } \\
\text { SD }\end{array}$ & $\begin{array}{c}29.73 \\
4.49\end{array}$ & $\begin{array}{c}26.65 \\
2.65\end{array}$ & $\begin{array}{c}25.17 \\
1.65\end{array}$ & $\begin{array}{c}27.16 \\
3.35\end{array}$ & $12.826 * * *$ \\
\hline $\begin{array}{l}\text { Distance to work } \\
\text { location }\end{array}$ & $\begin{array}{l}\text { Mean } \\
\text { SD }\end{array}$ & $\begin{array}{c}17.25 \\
8.85\end{array}$ & $\begin{array}{c}12.69 \\
8.56\end{array}$ & $\begin{array}{l}8.25 \\
4.93\end{array}$ & $\begin{array}{c}13.23 \\
8.65\end{array}$ & $5.307 * * *$ \\
\hline Work Experience & $\begin{array}{l}\text { Mean } \\
\text { SD }\end{array}$ & $\begin{array}{l}5.58 \\
3.47\end{array}$ & $\begin{array}{l}4.32 \\
2.82\end{array}$ & $\begin{array}{l}3.42 \\
1.38\end{array}$ & $\begin{array}{l}4.50 \\
2.90\end{array}$ & $2.850 *$ \\
\hline
\end{tabular}

Note: $*, * *$, and $* * *$ denotes significance level at $10 \%, 5 \%$, and $1 \%$.

Source: Own calculation based on field survey

\subsection{Relationship of selected factors with work motivation of DAs}

The relationship between work motivation of DAs and selected variables was tested using Pearson's Product Moment Correlation and the results are presented as follows.

\section{Recognition}

The result shows that about $66 \%$ of the DAs were discouraged by the existing recognition system in their institution while $20.5 \%$ were encouraged by the existing recognition system. The remaining $13.9 \%$ categorized themselves in the neutral position. The Chi-square analysis result indicated that recognition and work motivation are positively 
correlated at $1 \%$ significance level. Similarly, Pearson correlation (0.415) showed significant and strong correlation between the recognition system of the extension organizations and the work motivation of the DAs in the study area. From this result it is possible to conclude that DAs appear to be committed to their organizations and responsive to their duties and responsibilities by recognition and respect they received from their immediate bosses, colleagues and the farming community which they assist. This result is consistent with a study conducted by Girma (2018), Debebe et al. (2015), Belay et al. (2012), Tesfaye (2012), Zelalem (2011) and Yohannes (2009). Table 5: The association between recognition and work motivation levels of the DAs

\begin{tabular}{|c|c|c|c|c|c|c|c|c|c|c|}
\hline \multirow{3}{*}{ Recognition } & \multicolumn{8}{|c|}{ Work Motivation Level } & \multirow{3}{*}{$\chi^{2}$} & \multirow{3}{*}{$\mathbf{r}$} \\
\hline & \multicolumn{2}{|c|}{ Low } & \multicolumn{2}{|c|}{ Medium } & \multicolumn{2}{|c|}{ High } & \multicolumn{2}{|c|}{ Total } & & \\
\hline & f & $\%$ & $\mathbf{f}$ & $\%$ & f & $\%$ & f & $\%$ & & \\
\hline Highly discouraging & 8 & 6.6 & 10 & 8.2 & 0 & 0.0 & 18 & 14.8 & & \\
\hline Discouraging & 12 & 9.8 & 49 & 40.2 & 1 & 0.8 & 62 & 50.8 & & \\
\hline Neutral & 2 & 1.6 & 15 & 12.3 & 0 & 0.0 & 17 & 13.9 & & \\
\hline Encouraging & 4 & 3.3 & 10 & 8.2 & 9 & 7.4 & 23 & 18.9 & $56.103 * * *$ & $0.415 * * *$ \\
\hline Highly encouraging & 0 & 0.0 & 0 & 0.0 & 2 & 1.6 & 2 & 1.6 & & \\
\hline Total & 26 & 21.3 & 84 & 68.9 & 12 & 9.8 & 122 & 100.0 & & \\
\hline
\end{tabular}

Note: $\mathrm{f}=$ Frequencies, $\mathrm{r}=$ Pearson correlation; $*, * *, * *$ denotes significance level at $10 \%, 5 \%$, and $1 \%$.

Source: Own calculation based on field survey

\section{Promotion}

The analysis of the results from cross tabulation, chi-square and Pearson correlation indicate that the majority of the DAs $(75.5 \%)$ were discouraged the promotion criteria in their organization. The rest $18 \%$ were encouraged and $6.6 \%$ were neutral with the existing promotion criteria of their organization. It was also found that there is significant and positive association between promotion and work motivation of DAs at $1 \%$ level. This finding is consistent to a study by Debebe et al. (2015), Belay et al. (2012), McCaslin and Mwangi (1994). Key informants reveal that individuals' outstanding performance in addition to the service years should be considered as selection criteria for promotion, and this can help DAs to motivate more. Moreover, focus group discussants were raised their feelings of disillusionment with the promotions process in their organizations. They said that promotions were not based on merit, but rather on close relationship of DAs with their immediate bosses.

Table 6: The association between promotion and work motivation levels of the DAs

\begin{tabular}{|c|c|c|c|c|c|c|c|c|c|c|}
\hline \multirow{3}{*}{ Promotion } & \multicolumn{8}{|c|}{ Work Motivation Level } & \multirow{3}{*}{$\chi^{2}$} & \multirow{3}{*}{$\mathbf{r}$} \\
\hline & \multicolumn{2}{|c|}{ Low } & \multicolumn{2}{|c|}{ Medium } & \multicolumn{2}{|c|}{ High } & \multicolumn{2}{|c|}{ Total } & & \\
\hline & f & $\%$ & f & $\%$ & f & $\%$ & f & $\%$ & & \\
\hline Highly discouraging & 8 & 6.6 & 9 & 7.4 & 2 & 1.6 & 19 & 15.6 & & \\
\hline Discouraging & 13 & 10.7 & 60 & 49.2 & 0 & 0.0 & 73 & 59.9 & & \\
\hline Neutral & 1 & 0.8 & 7 & 5.7 & 0 & 0.9 & 8 & 6.6 & & \\
\hline Encouraging & 2 & 1.6 & 8 & 6.6 & 9 & 7.4 & 19 & 15.6 & $52.975 * * *$ & $0.305 * 2 \times$ \\
\hline Highly encouraging & 2 & 1.6 & 0 & 0.0 & 1 & 0.8 & 3 & 2.4 & & \\
\hline Total & 26 & 21.3 & 84 & 68.9 & 12 & 9.8 & 122 & 100.0 & & \\
\hline
\end{tabular}

Note: $\mathrm{f}=$ Frequencies, $\mathrm{r}=$ Pearson correlation; $* * *, * * *$ denotes significance level at $10 \%, 5 \%$, and $1 \%$.

Source: Own calculation based on field survey

\section{Dependable supervision}

Appropriate supervision was found to be one of the most important factors associated with work motivation of DAs. The presence of superiors can motivate DAs more to engage in to the work. Hence, DAs want their superiors to be more intelligent, experienced, matured, and having a good personality. Table 7 shows that about $25 \%$ of DAs were highly encouraged and motivated to perform their tasks with the availability of dependable supervisors while $47.5 \%$ of DAs described their feeling as below neutral range. The rest about $28 \%$ described their feeling as neutral. The statistical analysis also revealed that there is strong and significant association at $1 \%$ significant level between the availability of supervision and work motivation level of DAs. The result is in line with the previous studies conducted by Debebe et al. (2015), Belay et al. (2012), Tesfaye (2012), Zelalem (2011), and Yohannes (2009).

FGDs with DAs said that most supervisors' technical background might not be adequate to guide the DAs with different specializations (crop, livestock and natural resources management). It is also highly important supervision should be based on fields of specializations. Moreover, most supervisors lacked how big supervisions benefits and motivated DAs, they considered as a mechanism to finding faults. In addition to this, supervisors mostly spent their time in political activities and they did not have adequate time to support the DAs. Moreover, sometimes they did not want to go down to the grass root level in order to for solving our challenges arose from 
the farming community.

Table 7: The association between supervision and work motivation levels of the DAs

\begin{tabular}{|c|c|c|c|c|c|c|c|c|c|c|}
\hline \multirow{3}{*}{ Supervision } & \multicolumn{8}{|c|}{ Work Motivation Level } & \multirow{3}{*}{$\chi^{2}$} & \multirow{3}{*}{$\mathbf{r}$} \\
\hline & \multicolumn{2}{|c|}{ Low } & \multicolumn{2}{|c|}{ Medium } & \multicolumn{2}{|c|}{ High } & \multicolumn{2}{|c|}{ Total } & & \\
\hline & f & $\%$ & f & $\%$ & f & $\%$ & f & $\%$ & & \\
\hline Highly discouraging & 3 & 2.5 & 7 & 5.7 & 0 & 0.0 & 10 & 8.2 & & \\
\hline Discouraging & 13 & 10.7 & 34 & 27.9 & 1 & 0.8 & 48 & 39.3 & & \\
\hline Neutral & 5 & 4.1 & 28 & 22.9 & 1 & 0.8 & 34 & 27.9 & & \\
\hline Encouraging & 4 & 3.3 & 15 & 12.3 & 8 & 6.6 & 27 & 22.1 & $32.392 * * *$ & $0.306^{* * *}$ \\
\hline Highly encouraging & 1 & 0.8 & 0 & 0.0 & 2 & 1.6 & 3 & 2.5 & & \\
\hline Total & 26 & 21.3 & 84 & 68.9 & 12 & 9.8 & 122 & 100.0 & & \\
\hline
\end{tabular}

Note: $\mathrm{f}=$ Frequencies, $\mathrm{r}=$ Pearson correlation; $* * *, * * *$ denotes significance level at $10 \%, 5 \%$, and $1 \%$.

Source: Own calculation based on field survey

\section{Perception about salary}

This is about the DAs' perception of their salary received from the organization they current worked. Employees working with unfair pay may not be motivated and thus insufficient salary is the leading factor contributing to DA's decision to leave his/her job (Mowbray, 2002). According to Herzberg's motivational theory, salary was the most important factor influencing the work motivation of employees. Therefore, Pay-For-Performance (PFP) can positively motivate public employees who are less likely to find their work interesting (Weibel et al., 2010). The extension workers may be satisfied with their work, but they may still be discouraged with their monthly salary (Marsland et al., 1999). The result of the analysis described in Table 8 indicates that $86 \%$ of DAs were discouraged by the salary they received from their organization. And only $6.6 \%$ were encouraged by the salary they received whereas $7.3 \%$ of DAs were neutral. The Chi-square and Pearson correlation analysis result shows that there is a significant and positive association at $1 \%$ significant level between salary structure and work motivation of DAs. This finding is in line with Girma (2018) and Debebe et al. (2018) which indicated that low work motivation among DAs was aggravated by their poor salary of the extension organizations as compared to their counterparts in other sectors.

Table 8: The association between perceived pay structure and work motivation levels of the DAs

\begin{tabular}{|c|c|c|c|c|c|c|c|c|c|c|}
\hline \multirow{3}{*}{ Pay Structure } & \multicolumn{8}{|c|}{ Work Motivation Level } & \multirow{3}{*}{$\chi^{2}$} & \multirow{3}{*}{$\mathbf{r}$} \\
\hline & \multicolumn{2}{|c|}{ Low } & \multicolumn{2}{|c|}{ Medium } & \multicolumn{2}{|c|}{ High } & \multicolumn{2}{|c|}{ Total } & & \\
\hline & $\mathbf{f}$ & $\%$ & f & $\%$ & $\mathbf{f}$ & $\%$ & f & $\%$ & & \\
\hline Highly discouraging & 12 & 9.8 & 24 & 19.7 & 3 & 2.5 & 39 & 31.9 & & \\
\hline Discouraging & 13 & 10.7 & 49 & 40.2 & 4 & 3.3 & 66 & 54.1 & & \\
\hline Neutral & 0 & 0.0 & 7 & 5.7 & 2 & 1.6 & 9 & 7.3 & & \\
\hline Encouraging & 1 & 0.8 & 4 & 3.3 & 3 & 2.5 & 8 & 6.6 & $13.793^{* *}$ & $0.251 * * *$ \\
\hline Highly encouraging & 0 & 0.0 & 0 & 0.0 & 0 & 0.0 & 0 & 0.0 & & \\
\hline Total & 26 & 21.3 & 84 & 68.9 & 12 & 9.8 & 122 & 100.0 & & \\
\hline
\end{tabular}

Note: $\mathrm{f}=$ Frequencies, $\mathrm{r}=$ Pearson correlation; $*$, **, *** denotes significance level at $10 \%, 5 \%$, and $1 \%$.

Source: Own calculation based on field survey

\section{Work load}

The relationship between motivation of DAs and unrealistic workload was tested using chi-square and Pearson correlation and the results are provided in Table 8. The result of the analysis described in Table 9 shows that $73.8 \%$ of DAs were discouraged by the unrealistic workload performed while only $14.7 \%$ were encouraged by the unrealistic workload they performed. The analysis result shows that there is a significant and positive association at $1 \%$ significant level between the work load the DAs' performed and work motivation of DAs. Focus group discussants and key informants with DAs indicated that lack of clearly defined job descriptions thereby unrealistic workload is one of the challenges of DAs. Most of them have the opinion that they are overloaded by nonprofessional multiple tasks activities, but without incentives, which affected their work motivation. This multiple roles that DAs are currently playing signify the great burden that they are shouldering. Hence, if DAs are the forefront for rural transformation and in the country, their duties and responsibilities should be clearly defined and they should not be made to handle other tasks that will compromise their real professional integrity. 
Table 9: The association between work load and work motivation levels of the DAs

\begin{tabular}{|c|c|c|c|c|c|c|c|c|c|c|}
\hline \multirow{3}{*}{ Work load } & \multicolumn{8}{|c|}{ Work Motivation Level } & \multirow{3}{*}{$\chi 2$} & \multirow{3}{*}{$\mathbf{r}$} \\
\hline & \multicolumn{2}{|c|}{ Low } & \multicolumn{2}{|c|}{ Medium } & \multicolumn{2}{|c|}{ High } & \multicolumn{2}{|c|}{ Total } & & \\
\hline & f & $\%$ & f & $\%$ & f & $\%$ & f & $\%$ & & \\
\hline Highly discouraging & 5 & 4.1 & 11 & 9.0 & 0 & 0.0 & 16 & 13.1 & & \\
\hline Discouraging & 13 & 10.7 & 59 & 48.4 & 2 & 1.6 & 74 & 60.7 & & \\
\hline Neutral & 4 & 3.3 & 9 & 7.3 & 1 & 0.8 & 14 & 11.5 & & \\
\hline Encouraging & 2 & 1.6 & 5 & 4.1 & 9 & 7.3 & 16 & 13.1 & $54.690 * * *$ & $0.233 * * *$ \\
\hline Highly encouraging & 2 & 1.6 & 0 & 0.0 & 2 & 1.6 & 2 & 1.6 & & \\
\hline Total & 26 & 21.3 & 84 & 68.9 & 12 & 9.8 & 122 & 100.0 & & \\
\hline
\end{tabular}

Note: $\mathrm{f}=$ Frequencies, $\mathrm{r}=$ Pearson correlation; $*$, **, *** denotes significance level at $10 \%, 5 \%$, and $1 \%$.

Source: Own calculation based on field survey

\section{Achievements}

McClelland (1961) motivation theory expressed that while most people do not possess strong achievement-based motivation, those who do, display a consistent behavior in setting goals which they can influence with their efforts and ability, and as such the goal is considered to be achievable. In order to improve employees' motivation and increase staff performance, appropriate attention should be given to motivational factors by increasing the individual's sense of achievement and to demonstrate recognition of that achievement (Herzberg, 1968). As shown in Table 10, achievement motivation seems to be an important factor for DAs motivation in their work. The analysis shows that a majority of DAs (68.9\%) were highly motivated by the achievement in their work while only $5.7 \%$ of DAs were not motivated by the achievements in their work. The rest $25.4 \%$ of DAs were neither motivated nor de-motivated. The statistical result also indicates that there is strong association between senses of achievements with the work motivation at $1 \%$ significant level.

Table 10: The association between achievement and work motivation levels of the DAs

\begin{tabular}{|c|c|c|c|c|c|c|c|c|c|c|}
\hline \multirow{3}{*}{ Achievements } & \multicolumn{8}{|c|}{ Work Motivation Level } & \multirow{3}{*}{$\chi^{2}$} & \multirow{3}{*}{$\mathbf{r}$} \\
\hline & \multicolumn{2}{|c|}{ Low } & \multicolumn{2}{|c|}{ Medium } & \multicolumn{2}{|c|}{ High } & \multicolumn{2}{|c|}{ Total } & & \\
\hline & f & $\%$ & f & $\%$ & f & $\%$ & f & $\%$ & & \\
\hline Highly discouraging & 0 & 0.0 & 0 & 0.0 & 0 & 0.0 & 0 & 0.0 & & \\
\hline Discouraging & 2 & 1.6 & 5 & 4.1 & 0 & 0.0 & 7 & 5.7 & & \\
\hline Neutral & 7 & 5.7 & 23 & 18.9 & 1 & 0.8 & 31 & 25.4 & & \\
\hline Encouraging & 17 & 13.9 & 55 & 45.1 & 9 & 7.4 & 81 & 66.4 & $13.586^{* * *}$ & $0.173^{* * *}$ \\
\hline Highly encouraging & 0 & 0.0 & 1 & 0.8 & 2 & 1.6 & 3 & 2.5 & & \\
\hline Total & 26 & 21.3 & 84 & 68.9 & 12 & 9.8 & 122 & 100.0 & & \\
\hline
\end{tabular}

Note: $\mathrm{f}=$ Frequencies, $\mathrm{r}=$ Pearson correlation; ${ }^{*}, * *, * *$ denotes significance level at $10 \%, 5 \%$, and $1 \%$.

Source: Own calculation based on field survey

\section{Feeling of being involved}

Table 11 shows that the majority of DAs (73.8\%) were discouraged by the by-pass in the working and decision making process (planning, implementing and evaluation process). Only $13.9 \%$ of DAs were motivated by their involvement while $12.3 \%$ were neutral. The statistical analysis also indicates that there is strong association between feelings of being involved with the work motivation of DAs at $1 \%$ significant level. The findings are in line with the previous results reported by Belay et al. (2012), Tesfaye (2012), Zelalem (2011) and Yohannes (2009). Key informants and focus group discussants affirmed that most of the time DAs are considered as only implementers, they considered as a channel of technology transfer. But, a better participatory planning, implementing and evaluation process would help the DAs to own the programs and projects with higher sense on involvement, with more commitment and satisfaction. 
Table 11: The association between feeling of involvement and work motivation levels of DAs

\begin{tabular}{|c|c|c|c|c|c|c|c|c|c|c|}
\hline \multirow{3}{*}{ Involvement } & \multicolumn{8}{|c|}{ Work Motivation Level } & \multirow{3}{*}{$\chi^{2}$} & \multirow{3}{*}{$\mathbf{r}$} \\
\hline & \multicolumn{2}{|c|}{ Low } & \multicolumn{2}{|c|}{ Medium } & \multicolumn{2}{|c|}{ High } & \multicolumn{2}{|c|}{ Total } & & \\
\hline & $\mathbf{f}$ & $\%$ & f & $\%$ & $\mathbf{f}$ & $\%$ & f & $\%$ & & \\
\hline Highly discouraging & 5 & 4.1 & 15 & 12.3 & 1 & 0.8 & 21 & 17.2 & & \\
\hline Discouraging & 16 & 13.1 & 52 & 42.6 & 1 & 0.8 & 69 & 56.6 & & \\
\hline Neutral & 1 & 0.8 & 12 & 9.8 & 2 & 1.6 & 15 & 12.3 & & \\
\hline Encouraging & 3 & 2.5 & 5 & 4.1 & 8 & 6.6 & 16 & 13.1 & $41.339 * * *$ & $0.251 * * *$ \\
\hline Highly encouraging & 1 & 0.8 & 0 & 0.0 & 0 & 0.0 & 1 & 0.8 & & \\
\hline Total & 26 & 21.3 & 84 & 68.9 & 12 & 9.8 & 122 & 100.0 & & \\
\hline
\end{tabular}

Note: $\mathrm{f}=$ Frequencies, $\mathrm{r}=$ Pearson correlation; * $* *, * * *$ denotes significance level at $10 \%, 5 \%$, and $1 \%$.

Source: Own calculation based on field survey

\section{Working condition}

The statistical analysis result shows that the work condition was found to be very important motivational factor for DAs. The greater percentage of the DAs $(67.2 \%)$ was discouraged by the working conditions in their working place (organization). Only $19.6 \%$ of DAs were perceived the work condition was encouraged and motivated while $13.1 \%$ responded neither encouraged nor discouraged. The chi-square analysis shows that the association between working condition and work motivation of DAs is significant at $1 \%$ level. This result is consistent with the previous findings such as Girma (2018), Dessalegn (2014) and Yohannes (2009), concluded that work conditions and job prospects were the fundamental variables that many agricultural extension workers discouraged. Focus group discussants with DAs in the study areas affirmed that their professional tasks were constrained by the lack of these essential working facilities. Working facilities in farmer training centers (FTCs) to deliver practical trainings, demonstrations and exhibitions, transportation facilities and essential working facilities were lacked. In spite of adequate professional and technical competence, DAs were constrained to limit the accomplishment of job tasks due to the lack of these working facilities.

Table 12: The association between working conditions and work motivation levels of the DAs

\begin{tabular}{|c|c|c|c|c|c|c|c|c|c|c|}
\hline \multirow{3}{*}{ Working Condition } & \multicolumn{8}{|c|}{ Work Motivation Level } & \multirow{3}{*}{$\chi^{2}$} & \multirow{3}{*}{$\mathbf{r}$} \\
\hline & \multicolumn{2}{|c|}{ Low } & \multicolumn{2}{|c|}{ Medium } & \multicolumn{2}{|c|}{ High } & \multicolumn{2}{|c|}{ Total } & & \\
\hline & $\mathbf{f}$ & $\%$ & f & $\%$ & f & $\%$ & f & $\%$ & & \\
\hline Highly discouraging & 2 & 1.6 & 9 & 7.4 & 0 & 0.0 & 11 & 9.0 & \multirow{6}{*}{$19.003 * *$} & \multirow{6}{*}{0.069} \\
\hline Discouraging & 15 & 12.3 & 52 & 42.6 & 4 & 3.3 & 71 & 58.2 & & \\
\hline Neutral & 2 & 1.6 & 12 & 9.8 & 2 & 1.6 & 16 & 13.1 & & \\
\hline Encouraging & 5 & 4.1 & 11 & 9.0 & 6 & 4.9 & 22 & 18.0 & & \\
\hline Highly encouraging & 2 & 1.6 & 0 & 0.0 & 0 & 0.0 & 2 & 1.6 & & \\
\hline Total & 26 & 21.3 & 84 & 68.9 & 12 & 9.8 & 122 & 100.0 & & \\
\hline
\end{tabular}

Note: $\mathrm{f}=$ Frequencies, $\mathrm{r}=$ Pearson correlation; $* * *, * * *$ denotes significance level at $10 \%, 5 \%$, and $1 \%$.

Source: Own calculation based on field survey

\section{Attitude of DAs towards their Job}

The association between the attitudes of DAs towards their job and work motivation of DAs was analyzed by using chi-square and Pearson's product moment correlation. Table 13 shows that $65.6 \%$ of DAs was discouraged by their work while only $15.6 \%$ of them were encouraged. The result from the analysis confirmed that there is association among the attitudes of DAs towards their job and work motivation levels of DAs at 5\% significant level. This indicates that there was less job satisfaction as DAs in the study area. This finding is similar to a study by Girma (2018), Belay et al. (2012), Tesfaye (2012). In contrast to this, Zelalem (2011) found that there was better quality of work life in an extension organization of Benishangul Gumuz. 
Table 13: The association between attitude of DAs towards their job and their work motivation

\begin{tabular}{|c|c|c|c|c|c|c|c|c|c|c|}
\hline \multirow{3}{*}{$\begin{array}{l}\text { Attitudes of DAs } \\
\text { towards their Job }\end{array}$} & \multicolumn{8}{|c|}{ Work Motivation Level } & \multirow{3}{*}{$\chi^{2}$} & \multirow{3}{*}{$\mathbf{r}$} \\
\hline & \multicolumn{2}{|c|}{ Low } & \multicolumn{2}{|c|}{ Medium } & \multicolumn{2}{|c|}{ High } & \multicolumn{2}{|c|}{ Total } & & \\
\hline & $\mathbf{f}$ & $\%$ & f & $\%$ & f & $\%$ & f & $\%$ & & \\
\hline Highly discouraging & 2 & 1.6 & 10 & 8.2 & 1 & 0.8 & 13 & 10.7 & & \\
\hline Discouraging & 16 & 13.1 & 51 & 41.8 & 0 & 0.0 & 67 & 54.9 & & \\
\hline Neutral & 3 & 2.5 & 16 & 13.1 & 4 & 3.3 & 23 & 18.9 & & \\
\hline Encouraging & 4 & 3.3 & 5 & 4.1 & 5 & 4.1 & 14 & 11.5 & $27.128^{* *}$ & $0.203^{* *}$ \\
\hline Highly encouraging & 1 & 0.8 & 2 & 1.6 & 2 & 1.6 & 5 & 4.1 & & \\
\hline Total & 26 & 21.3 & 84 & 68.9 & 12 & 9.8 & 122 & 100.0 & & \\
\hline
\end{tabular}

Note: $\mathrm{f}=$ Frequencies, $\mathrm{r}=$ Pearson correlation; $*$, **, *** denotes significance level at $10 \%, 5 \%$, and $1 \%$.

Source: Own calculation based on field survey

\section{Conclusion}

Motivated DAs feel less anxiety, enjoy their work and have better physical and mental strength to accomplish the tasks. Besides, motivated DAs are more committed to their extension organizations and show less insubordination and grievance. Yet, the result of this research revealed that majority of agricultural DAs were belongs to low and medium level of motivation to work. DAs' socio-demographic factors, organizational, work-related environments, and psychological factors in agricultural extension organization were equally responsible for the existing undesirable consequences of lower work motivation level of DAs. Therefore, necessary efforts have to be made to improve work motivation of DAs in the extension organization. Thus, concerned agricultural policy makers, extension managers, and supervisors should conduct periodic assessments work motivation of DA's and have to plan for improvement.

\section{References}

ATA, MoA \& EIAR (2015). Strategy to improve Ethiopia's National Agricultural Research System (NARS): Vision, systemic bottlenecks, strategic interventions and implementation framework, Addis Ababa.

Belay, K., \& Deginet, A. (2004). Challenges facing agricultural extension agents: A Case Study from Southwestern Ethiopia. African development review, 16(1), 139-168.

Belay, K., Ranjan, S., Dawit, A., Abera, D., \& Jemal, Y. (2012). Work motivation and job performance of development agents in Ethiopia. Rural Capacity Building Project Ministry of Agriculture, Addis Ababa, Ethiopia.

CSA (2020). Agricultural sample survey 2019/20 report on area and production of major crops for private peasant holdings, Meher season, volume I. Central Statistical Agency Addis Ababa.

CSA \& WFP (2019). Comprehensive Food Security and Vulnerability Analysis (CFSVA). Ethiopia, WFP and Headquarters, WFP.

Davis, K., Swanson, B., Amudavi, D., Mekonnen, D. A., Flohrs, A., Riese, J., ... \& Elias Zerfu (2010). In-depth assessment of the public agricultural extension system of Ethiopia and recommendations for improvement. International Food Policy Research Institute (IFPRI) Discussion Paper, 1041.

Debebe, C., Okoyo, E., \& Jemal, Y. (2016). Factors influencing work motivation of development agents: The case of Agarfa and Sinana Districts, Bale Zone, Oromia Regional State, Ethiopia. International Journal of Agricultural Science Research, 5(1), 1-18.

Dercon, S., Gilligan, D., Hoddinott, J., \& Woldehanna, T. (2009). The impact of agricultural extension and roads on poverty and consumption growth in fifteen Ethiopian villages. American Journal of Agricultural Economics, 91(4), 1007-1021.

Dessalegn, G. (2014). Analyzing Determinants of Development Agents' Motivation in Agricultural Extension Services Provision: A Case from South West Shoa Zone, Oromia Regional State, Ethiopia: An Ordered logit Regression Model approach. International Journal of Agricultural Extension and Rural Development, 1(3), 026-030

Fantu, N., Guush, B., Minten, B., \& Alemayehu, S. (2015). Agricultural growth in Ethiopia (2004-2014): In Working paper 81. Addis Ababa: IFPRI-ESSP.

Gerba, L. (2018). The Ethiopian Agricultural Extension System and Its Role as Development Actor: Cases from Southwestern Ethiopia (Doctoral dissertation, Universitäts-und Landesbibliothek Bonn).

Getachew, D. (2018). Overcoming agricultural and food crises in Ethiopia: Institutional evolution and the path to agricultural transformation. Master Printing Press.

Girma, A. (2018). Work Motivation among Agricultural Development Agents in Jaldu Woreda, Ethiopia. Public Policy and Administration Research, 8(12), 22-36.

Herzberg, F.W. (1966). Work and nature of work.Clevelan; World publishing Company. 
Marsland, D.W., Syptak, J.M., \& Ulmer, D. (1999). Job satisfaction: Putting theory into practice. Family Practice Manag. J., 6(9), 102-108.

McCaslin, V. L., \& Mwangi, J. (1994). Job satisfaction of Kenya's rift valley extension agents. Journal of Extension, 32(3), 1-13.

McClelland, D.C. (1961). The achieving society. Prince-Hall Inc.: New Jersy

MoA (2020). Agriculture sector investment prioritization (2019/20-2024/25). Ministry of Agriculture, Addis Ababa.

MoANR \& ATA (2017). Ethiopia's agricultural extension strategy: Vision, systemic bottleneck and priority intervention. Ministry of Agriculture and Natural Resources and Agriculture Transformation Agency, Addis Ababa.

Mowbray, J. M. (2002). Factors affecting turnover of county Extension agents in the University of Kentucky Cooperative Extension Service. University of Kentucky.

NBE (2019/20). Annual report of 2019/20. National Bank of Ethiopia, Addis Ababa, Ethiopia.

Pareek, U., \& Rao, L. (1992). Work motivation and management decision. Concept publishing company, New Delhi.

Pye-Smith, C. (2012). Agricultural extension: A time for change: Linking knowledge to policy and action for food and livelihoods. CTA.

Spies, M. (2006). Distance between home and workplace as a factor for job satisfaction in the North-West Russian oil industry. Fennia-International Journal of Geography, 184(2), 133-149.

Tesfaye, G. (2012). Work motivation and job performance of development agents in agro-pastoral areas: The case of Bule Hora district, Borana Zone, Ethiopia. An MSc thesis presented to School of Graduate Studies, Haramaya University.

Thurstone, L.L. (1976). Attitudes Scale, In Measurement of Extension Research: Instrument Developed at IARI, 1963-72. IARI: New Delhi.

Weibel, A., Rost, K., \& Osterloh, M. (2010). Pay for performance in the public sector-Benefits and (hidden) costs. Journal of public administration research and theory, 20(2), 387-412.

Zelalem, B. (2011). Factors influencing work motivation of development agents, Assosa zone, Benishangul Gumuz Regional State, Ethiopia. An MSc thesis presented to School of Graduate Studies of Haramaya University.

Yohannes, M. (2009). Factors influencing work motivation of development agents in Burji and Konso special woredas. An MSc thesis Presented to the School of Graduate Studies of Haramaya University. 